\title{
Omalizumab: the evidence for its place in the treatment of allergic asthma
}

\author{
Diarmuid M. McNicholl, Liam G. Heaney
}

Regional Respiratory Centre, Belfast City Hospital, Belfast, UK

\begin{abstract}
Introduction: Asthma is a chronic inflammatory airways disease associated with reversible airflow obstruction and bronchial hyperresponsiveness. Asthma is prevalent worldwide and results in significant morbidity, mortality, and healthcare costs, the majority of which arise from those with severe disease. Omalizumab is a monoclonal antibody to immunoglobulin $\mathrm{E}$ (IgE) that has been developed for the treatment of severe persistent allergic (IgE mediated) asthma.

Aims: The aim of this review is to evaluate the available clinical evidence on omalizumab to determine the role it has to play in the treatment of persistent allergic asthma.

Evidence review: There is clear evidence to show that omalizumab is effective in reducing the rate of asthma exacerbations, inhaled corticosteroid dose, and the need for rescue medication in patients with allergic asthma. Clinical data indicate beneficial effects on patient-reported symptoms and perceived quality of life, as well as a reduction in unscheduled healthcare visits. There is little evidence to suggest omalizumab may enhance lung function or reduce the requirement for oral corticosteroids. Omalizumab has a favorable safety profile, although anaphylaxis has occurred. A study in children showed similar results to those achieved in adults and adolescents, with fewer asthma exacerbations and school days missed. Omalizumab may be cost effective in patients when used as add-on therapy to inhaled corticosteroids and long-acting beta ${ }_{2}$ agonists (LABA).
\end{abstract}

Place in therapy: Omalizumab is an effective add-on therapy to inhaled corticosteroids and LABAs in adults and adolescents with severe persistent allergic asthma. Currently there is insufficient evidence to support the use of omalizumab in children.

Core Evidence. 2008;3(1):55-66

doi: $10.3355 /$ ce. 2008.012

Key words: allergic asthma, omalizumab, immunoglobulin E, evidence

| Core evidence place in therapy summary for omalizumab in the treatment of allergic asthma

\begin{tabular}{|c|c|c|}
\hline Outcome measure & Evidence & Implications \\
\hline \multicolumn{3}{|l|}{ Patient-oriented evidence } \\
\hline Reduction in inhaled corticosteroid medication & Clear & Effective inhaled corticosteroid sparing agent \\
\hline Reduction in asthma exacerbations & Clear & $\begin{array}{l}\text { Fewer exacerbations when used as add-on therapy to inhaled } \\
\text { corticosteroids with or without long-acting beta }{ }_{2} \text { agonists }\end{array}$ \\
\hline Reduction in rescue medication & Clear & Effective in decreasing the need for rescue medication \\
\hline Reduction in emergency room visits and hospitalization & Clear & Fewer unscheduled healthcare visits when compared with placebo \\
\hline Improvement in asthma symptoms & Substantial & $\begin{array}{l}\text { Significant reduction from baseline symptoms in adults but not shown } \\
\text { in children }\end{array}$ \\
\hline Reduction in oral corticosteroid use & No evidence & Evidence required \\
\hline \multicolumn{3}{|l|}{ Disease-oriented evidence } \\
\hline Improvement in lung function & Limited & May improve $\mathrm{FEV}_{1}$ and morning PEF \\
\hline Improvement in asthma-related quality of life score & Substantial & Beneficial effects on patient perceived quality of life \\
\hline \multicolumn{3}{|l|}{ Economic evidence } \\
\hline \multirow{2}{*}{$\begin{array}{l}\text { Cost effective as add-on therapy to inhaled } \\
\text { corticosteroids and long-acting beta }{ }_{2} \text { agonists in severe } \\
\text { persistent allergic asthma }\end{array}$} & \multirow[t]{2}{*}{ Limited } & $£ 38900$ per QALY gained \\
\hline & & $\begin{array}{l}\text { May be cost effective in those with an elevated risk of asthma- } \\
\text { related mortality }\end{array}$ \\
\hline
\end{tabular}




\section{Scope, aims, and objectives}

Omalizumab (Xolair ${ }^{\circledR}$, Novartis Pharma AG) is a recombinant DNA-derived humanized immunoglobulin $\mathrm{G}$ ( $\mathrm{ggG}$ ) 1k monoclonal antibody that selectively binds to human immunoglobulin $\mathrm{E}(\mathrm{IgE})$ and has been developed for the treatment of allergic asthma. It binds to $\lg E$ at the high affinity $\lg E$ receptor-binding site, forming immune complexes with free lgE (Presta et al. 1993). This binding inhibits interaction of $\lg E$ with $\lg E$ receptors on the surface of mast cells, basophils, and other cell types, preventing the release of inflammatory mediators that occur in allergic asthma.

The purpose of this article is to review the evidence behind the use of omalizumab in the treatment of allergic asthma, including its effects on outcomes such as reduction of corticosteroid use, asthma exacerbation rates, and lung function.

\section{Methods}

The English language literature was reviewed for appropriate articles relating to omalizumab for the treatment of asthma. The following databases were searched during July 2007 using the search terms "(Omalizumab OR Xolair) AND asthma":

- PubMed, http://www.ncbi.nlm.nih.gov/sites/entrez?db= pubmed

- Cochrane Database of Systematic Reviews (CDSR), http://www.cochrane.org/index0.htm

- National Institute for Health and Clinical Excellence (NICE), www.nice.org.uk

- National Guideline Clearing House, www.guideline.gov

Only studies in patients with asthma were included and no date limitations were placed on the search.

Several guidelines relating to asthma management were identified, however, only two recent guidelines applicable on a worldwide scale were considered relevant to this review.

Two hundred and eighteen full papers were identified in the initial search. Records were manually reviewed and a total of 173 were excluded: nonsystematic reviews $(n=129)$, in-vitro studies $(n=3)$, letters and editorials $(n=7)$, and articles that mentioned omalizumab but did not investigate its clinical use in asthma $(n=34)$. Review of the reference lists of systematic review and meta analysis studies yielded six additional studies. One economic reference was published after the initial literature search was performed and was included in this review (NICE 2007). A total of 47 abstracts were retrieved and were also manually reviewed. Forty-two were excluded: duplicate publications of data presented in full papers $(n=34)$, in-vitro studies $(n=1)$, or studies that did not investigate the clinical use of omalizumab in asthma $(n=7)$ (Table 1$)$.

\section{Disease overview}

Asthma is a chronic inflammatory disorder of the airways characterized by airflow limitation, airway hyperresponsiveness, and inflammation of the bronchi. To establish a diagnosis there
Table 1 | Evidence base included in the review

\begin{tabular}{|lcc|} 
& \multicolumn{2}{c|}{ Number of records } \\
\cline { 2 - 3 } Category & Full papers & Abstracts \\
\hline Initial search & 218 & 47 \\
records excluded & 173 & 42 \\
$\quad$ records included & 45 & 5 \\
Additional studies identified ${ }^{\text {a }}$ & 7 & 0 \\
Total records included & 52 & 5 \\
Level 1 clinical evidence & 8 & 0 \\
Level 2 clinical evidence & 31 & 4 \\
Level $\geq 3$ clinical evidence & 8 & 1 \\
$\quad$ trials other than RCT & 3 & 1 \\
$\quad$ case reports & 5 & 0 \\
Economic evidence & 5 & 0 \\
\hline aAdditional studies identified equals any relevant study that was identified from a source \\
other than the main searches, e.g. a reference list. For definition of levels of evidence, see \\
inside back cover or website (http://www.coremedicalpublishing.com). \\
RCT, randomized controlled trial.
\end{tabular}

must be the presence of episodic symptoms of airflow obstruction, evidence of at least partially reversible airflow obstruction, and the exclusion of alternative diagnoses (Anon 1992). The World Health Organization (WHO) estimates that 300 million people suffer from asthma and 250000 people die annually worldwide from asthma (GINA 2006a). Asthma is a significant burden, not only in terms of healthcare costs but also from lost productivity and reduced participation in family life. The economic cost of asthma is considerable comprising both direct medical costs such as hospital admissions and the cost of medication, and indirect medical costs such as time lost from work and premature death. The number of disability-adjusted life years (DALYs) lost due to asthma worldwide has been estimated to be about 15 million per year. Worldwide asthma accounts for around 1\% of all DALYs lost, reflecting the high prevalence and severity of asthma (Masoli et al. 2004).

There are 10.1 million people in the British Isles who suffer from asthma with a mean prevalence of clinical asthma estimated at $16.1 \%$, which is among the highest rates of asthma in the world (Masoli et al. 2004). The incidence of asthma diagnosed over the last few decades has markedly increased, such that it is now about five times higher than it was 25 years ago. The total cost of asthma in the British Isles has been estimated to be about $£ 2.5$ billion, including a cost of around $£ 900$ million to the public health service (Masoli et al. 2004). It is estimated that $50 \%$ of all annual healthcare costs for asthma come from the most severe $20 \%$ of the asthmatic population. About 20 million working days are lost to asthma each year (Masoli et al. 2004).

\section{Pathophysiology}

Airway inflammation involves cellular infiltration of eosinophils and lymphocytes; changes in resident cells including mast cell sensitization and smooth muscle hypertrophy; and airway wall changes with collagen deposition and airway remodeling. 
A network of cytokines and growth factors orchestrates this bronchial inflammation resulting in the airway obstruction and bronchial hyperresponsiveness that characterizes asthma (Drazen 2007).

IgE plays a central role in allergic asthma. Allergic sensitization results from the formation of specific IgE in response to common inhaled allergens such as pollen and house dust mites. IgE formation is stimulated by the release of interleukin 4 (IL-4) and interleukin 13 (IL-13) produced by several cell types including a subset of T-helper lymphocytes prevalent in atopy called Th2 cells (Guachat et al. 1990; de Vries et al. 1999). Specific IgE released from $B$ lymphocytes circulates and binds to specific high-affinity receptors (Fc-epilson-RI) on the surface of mast cells and basophils. IgE is activated by the cross bridging of protein allergens resulting in the release of histamine and increased synthesis of inflammatory mediators such as prostaglandins, causing bronchoconstriction and plasma exudate in allergic asthmatic patients (Turner \& Kinet 1999). In order to inhibit this mechanism it is essential to effectively eradicate circulating $\mathrm{IgE}$, as there are 10000 to 1000000 Fc-epsilon-RI on mast cells and basophils and nearly all are occupied by lgE. Only $2000 \mathrm{lgE}$ molecules are needed for half maximal release of histamine from basophils (Barnes 2007; MacGlashan 1993).

\section{Current therapy options}

The mainstay of pharmacologic treatment of asthma involves the use of inhaled bronchodilators and corticosteroids with the titration of the dose and the introduction of additional therapies occurring in a stepwise fashion. The aim of pharmacologic management of asthma is to control symptoms, prevent exacerbations, and achieve the best possible pulmonary function with minimal side effects. In the UK, the British Thoracic Society (BTS) and Scottish Intercollegiate Guidelines Network (SIGN) have produced a set of stepwise guidelines using evidence-based methodology that aim to eradicate symptoms as quickly as possible and optimize peak flow (BTS, SIGN 2007). These guidelines have become the cornerstone of asthma treatment within the NHS. On a worldwide scale the Global Initiative for Asthma (GINA) has produced a global strategy for asthma management and prevention (GINA 2006a). They too have incorporated a management framework based on clinical control that uses a stepwise approach. Both sets of guidelines are very similar and aim to achieve and maintain asthma control by stepping up treatment as necessary and stepping down when control is good (see Figs. 1 and 2).

\section{Unmet needs}

Approximately $5-10 \%$ of asthmatic patients remain symptomatic despite treatment at step 4 or step 5 of the BTS/SIGN guidelines (BTS, SIGN 2007), and are referred to as having "difficult asthma". Multidisciplinary evaluation protocols have demonstrated that approximately $50 \%$ of this difficult to control population have identifiable factors contributing to poor control, such as nonadherence, alternative/additional diagnoses or contributing comorbidities such as nasal disease, or psychosocial factors (Heaney et al. 2003; Robinson et al. 2003). The remaining patients

\begin{tabular}{|c|c|}
\hline \multirow[t]{2}{*}{ Step 1} & Mild intermittent asthma \\
\hline & Inhaled short-acting beta ${ }_{2}$ agonists as required \\
\hline \multirow[t]{4}{*}{ Step 2} & Regular preventer therapy \\
\hline & Add inhaled steroid $200-800 \mathrm{mcg} / \mathrm{day}^{\mathrm{a}}$ \\
\hline & $400 \mathrm{mcg}$ is an appropriate starting dose for many patients \\
\hline & $\begin{array}{l}\text { Start at the dose of inhaled steroid appropriate to severity } \\
\text { of disease }\end{array}$ \\
\hline \multirow[t]{7}{*}{ Step 3} & Add-on therapy \\
\hline & Add inhaled LABA \\
\hline & Assess control of asthma: \\
\hline & - good response to LABA - continue LABA \\
\hline & $\begin{array}{l}\text { - benefit from LABA but control still inadequate - continue } \\
\text { LABA and increase inhaled steroid dose to } 800 \mathrm{mcg} / \text { daya }\end{array}$ \\
\hline & $\begin{array}{l}\text { - no response to LABA - stop LABA and increase inhaled } \\
\text { steroid to } 800 \mathrm{mcg} / \text { day }^{a}\end{array}$ \\
\hline & $\begin{array}{l}\text { - if control still inadequate, institute trial of other therapies, } \\
\text { e.g. leukotriene receptor antagonist or SR theophylline }\end{array}$ \\
\hline \multirow[t]{3}{*}{ Step 4} & Persistent poor control \\
\hline & Increase inhaled steroid up to $2000 \mathrm{mcg} /$ day $^{\mathrm{a}}$ \\
\hline & $\begin{array}{l}\text { Add a fourth drug e.g. leukotriene receptor antagonist, SR } \\
\text { theophylline, beta }{ }_{2} \text { agonist tablet }\end{array}$ \\
\hline \multirow[t]{5}{*}{ Step 5} & Continuous or frequent use of oral steroids \\
\hline & $\begin{array}{l}\text { Use daily steroid tablet in the lowest dose providing } \\
\text { adequate control }\end{array}$ \\
\hline & Maintain high dose inhaled steroid at $2000 \mathrm{mcg} / \mathrm{day}^{\mathrm{a}}$ \\
\hline & $\begin{array}{l}\text { Consider other treatments to minimize the use of } \\
\text { steroid tablets }\end{array}$ \\
\hline & Refer patient for specialist care \\
\hline
\end{tabular}

Fig. 1 | BTS/SIGN Guidelines: summary of stepwise management of asthma in adults (BTS, SIGN 2007). Patients should start treatment at the step most appropriate to the initial severity of their asthma.

aBeclomethasone dose or equivalent. BTS/SIGN, British Thoracic Society/Scottish Intercollegiate Guidelines Network; LABA, long-acting beta ${ }_{2}$ agonist; SR, sustained release.

have refractory asthma or therapy-resistant disease, where new therapeutic options are required.

The American Thoracic Society (ATS 2000) uses major and minor diagnostic characteristics to define refractory asthma. The patient should have symptoms of mild-to-moderate persistent asthma despite treatment with continuous or near continuous $\geq 50 \%$ of the year) oral corticosteroids or high-dose inhaled steroids equivalent to $>1260 \mathrm{mcg} /$ day beclomethasone dipropionate. They must also display two minor characteristics from the following list: requirement for additional long-acting beta ${ }_{2}$ agonists (LABA), theophylline, or leukotriene anatagonist; symptoms requiring short-acting beta ${ }_{2}$ agonist on a daily or near-daily basis; persistent airway obstruction [forced expiratory volume in $1 \mathrm{~s}\left(\mathrm{FEV}_{1}\right)$ $<80 \%$ predicted; diurnal variability $>20 \%$ ]; one or more urgent care visits for asthma per year; three or more oral steroid bursts per year; prompt deterioration on reducing inhaled steroid dose; or a near-fatal asthma event in the past. Other conditions must have been excluded, exacerbation factors treated, and patients 


\begin{tabular}{|ll|}
\hline Level of control & Treatment action \\
\hline Controlled & Maintain and find lowest controlling step \\
Partly controlled & Consider stepping up to gain control \\
Uncontrolled & Step up until controlled \\
Exacarbation & Treat as exacerbation \\
& \\
Treatment steps ${ }^{\mathrm{a}}$ & \\
Asthma education & \\
Environmental control & \\
Step 1 & As needed rapid-acting beta ${ }_{2}$ agonists \\
Step 2 & As needed rapid-acting beta ${ }_{2}$ agonists + one from \\
& the following: \\
& $\begin{array}{l}\text { - low-dose inhaled ICS } \\
\text { - leukotriene modifier }\end{array}$ \\
& As needed rapid-acting beta ${ }_{2}$ agonists + one from \\
the following: \\
Step 3
\end{tabular}

Fig. 2 | GINA Guidelines: management approach based on control for children older than 5 years, adolescents, and adults (GINA 2006a).

aFor steps 2, 3, and 4 the preferred controller is the first option. ${ }^{b}$ Receptor antagonist or synthesis inhibitors.

GINA, Global Initiative for Asthma; IgE, immunoglobulin; ICS, inhaled glucocorticosteroid; LABA, long-acting beta ${ }_{2}$ agonist; SR, sustained release.

felt to be generally adherent with their medication for this definition of refractory asthma.

This group of patients is at a high risk of asthma death, account for a substantial proportion of the total cost of asthma, and have significantly impaired quality of life. Omalizumab and other novel therapies may have a potential role in this group of subjects.

\section{Clinical evidence with omalizumab}

\section{Effect on IgE levels}

Aerosolizing omalizumab is an ineffective method for the administration of this agent, principally as it does not reduce serum free lgE levels regardless of low-dose (1 mg) or high-dose (10 mg) therapy. It was no more effective than placebo in improving lung function and reducing a bronchial allergen challenge (Fahy et al. 1999). Subcutaneous and intravenous delivery of omalizumab however causes significant reductions in serum free lgE, ranging from $89 \%$ to $99 \%$ irrespective of different dosing regimens within different trials (Walker et al. 2006). One study showed a rapid and sustained fall in free serum IgE of $96 \%$ following $100 \mathrm{mg}$ of intravenous omalizumab, with a mean recovery of $50 \%$ by 39 days (Corne et al. 1997). Doses ranging from 0.0005 to $0.14 \mathrm{mg} / \mathrm{kg}$ subcutaneously or 0.05 to $1.0 \mathrm{mg} / \mathrm{kg}$ intravenously decrease free serum IgE levels in plasma in a dose-dependent fashion in both adults and children (Barnes 2000; Fahy 2000). Comparison of intravenous administration of omalizumab with placebo in patients with mild asthma not receiving inhaled corticosteroids resulted in a significant decrease in serum free IgE levels from baseline concentrations $(P<0.00001$ and $P<0.001$ in two separate studies) (Boulet et al. 1997; Fahy et al. 1997). No change in serum free IgE was reported in the placebo groups. Intravenous omalizumab also caused a significant improvement in patients' response to a methacholine challenge, which was not observed in the control group (Boulet et al. 1997). No significant difference was detected in the use of rescue medication or improvements in lung function.

Subcutaneous omalizumab also results in significantly lower free IgE levels compared with placebo. No significant difference occurred in terms of change in $\mathrm{FEV}_{1}$ or response to a methacholine challenge between omalizumab and placebo in patients with mild asthma and not on inhaled corticosteroids (van Rensen et al. 2005; Prieto et al. 2006). However, one study reported a significant difference in the allergen-induced late phase response in patients treated with omalizumab (van Rensen et al. 2005).

\section{Moderate-to-severe asthma}

The effects of omalizumab on asthma exacerbation and steroid use are summarized in Tables 2 and 3.

Busse et al. (2001) performed a double-blind, placebocontrolled trial in 525 patients with moderate-to-severe allergic asthma requiring daily inhaled corticosteroids (beclomethasone dipropionate). There was a 4-6 week run in, in which patients were changed from their prescribed inhaled corticosteroids to an equivalent dose of beclomethasone dipropionate with stabilization. Following this, patients were randomized to receive placebo or subcutaneous omalizumab $0.016 \mathrm{mg} / \mathrm{kg} \mathrm{lgE}(\mathrm{IU} / \mathrm{mL})$ every 4 weeks. A steroid stable phase of 16 weeks was followed by a 12-week steroid reduction phase, where the inhaled corticosteroid was tapered to the lowest dose. During the stable phase, significantly fewer omalizumab recipients than placebo experienced one or more exacerbations (14.6\% versus $23.3 \%$, respectively; $P=0.009)$, and there were significantly fewer asthma exacerbations per patient ( 0.28 versus $0.54 ; P=0.006)$. These outcomes also occurred during the steroid reduction phase ( $21.3 \%$ versus $32.3 \%, P=0.004$, and 0.39 versus $0.66, P=0.003$, respectively). Steroid reduction was significantly greater with omalizumab treatment than with placebo (median $75 \%$ versus $50 \% ; P<0.001)$. The number of patients receiving omalizumab who were able to withdraw from inhaled steroid use was twice that of those in the placebo group (39.6\% versus $19.1 \%$; $P<0.001)$. Omalizumab also significantly improved daily asthma scores and reduced rescue medication use in comparison with placebo. 


\begin{tabular}{|c|c|c|c|c|c|}
\hline \multirow[t]{2}{*}{ Asthma severity } & \multirow[t]{2}{*}{ Study } & \multirow[t]{2}{*}{ Steroid use } & \multicolumn{3}{|c|}{ Exacerbations (mean per patient) } \\
\hline & & & Placebo & Omalizumab & $P$ value \\
\hline \multirow[t]{7}{*}{ Moderate/severe } & \multirow[t]{2}{*}{ Busse et al. 2001} & Steroid stable & 0.54 & 0.28 & 0.006 \\
\hline & & Steroid reduction & 0.66 & 0.39 & 0.003 \\
\hline & \multirow[t]{2}{*}{ Solèr et al. 2001} & Steroid stable & 0.66 & 0.28 & $<0.001$ \\
\hline & & Steroid reduction & 0.75 & 0.36 & $<0.001$ \\
\hline & Vignola et al. 2004 (asthma and allergic rhinitis) & - & 0.25 & 0.40 & 0.02 \\
\hline & \multirow[t]{2}{*}{ Milgrom et al. 2001 (childhood asthma) } & Steroid stable & 0.40 & 0.30 & 0.093 \\
\hline & & Steroid reduction & 0.72 & 0.42 & $<0.001$ \\
\hline \multirow[t]{3}{*}{ Severe } & \multirow[t]{2}{*}{ Holgate et al. 2004} & Steroid stable & 0.23 & 0.15 & - \\
\hline & & Steroid reduction & 0.34 & 0.19 & - \\
\hline & Humbert et al. 2005 & - & 0.91 & 0.68 & $0.42^{\mathrm{a}}$ \\
\hline
\end{tabular}

Table 3 | Inhaled corticosteroid reduction with omalizumab in placebo-controlled trials in allergic asthma

\begin{tabular}{|c|c|c|c|c|c|c|c|}
\hline \multirow[t]{2}{*}{ Asthma severity } & \multirow[t]{2}{*}{ Study } & \multicolumn{3}{|c|}{ Patients $(\%)$ reducing inhaled steroid dose by $\geq \mathbf{5 0} \%$} & \multicolumn{3}{|c|}{ Patients (\%) withdrawing inhaled steroids } \\
\hline & & Placebo & Omalizumab & $P$ value & Placebo & Omalizumab & $P$ value \\
\hline \multirow[t]{3}{*}{ Moderate/severe } & Busse et al. 2001 & 55 & 72 & $<0.001$ & 19 & 40 & 0.003 \\
\hline & Solèr et al. 2001 & 55 & 79 & - & 19 & 43 & - \\
\hline & Milgrom et al. 2001 & 66.7 & 100.0 & 0.001 & 39.0 & 55.0 & 0.004 \\
\hline Severe & Holgate et al. 2004 & 51 & 74 & 0.001 & 15 & 21 & 0.198 \\
\hline
\end{tabular}

Solèr et al. (2001), conducted a similar investigation in 546 allergic asthmatics, aged $12-76$ years who were symptomatic despite inhaled corticosteroids (500-1200 mcg of beclomethasone dipropionate). The same methods as the Busse et al. (2001) study were used, with a 16-week steroid stable phase and a 12-week steroid reduction phase. The omalizumab group, again, had significantly fewer asthma exacerbations per patient and fewer experienced one or more exacerbations in the steroid stable phase compared with the placebo group ( 0.28 versus 0.66 , $P<0.001$, and $12.8 \%$ versus $30.5 \%, P<0.001$, respectively). This pattern continued in the steroid reduction phase $(0.36$ versus $0.75, P<0.001$, and $15.7 \%$ versus $29.8 \%, P<0.001$, respectively). The proportion of patients who were able to reduce the dose of steroids was significantly higher in the omalizumab group than in the placebo group $(P<0.001)$. Furthermore, $43 \%$ of patients on omalizumab withdrew inhaled steroids completely compared with $19 \%$ on placebo. Significant improvements in symptom scores and use of rescue medication occurred in the omalizumab group compared with the placebo group despite the more marked reduction in dosage of beclomethasone dipropionate.

Extensions to the original investigations by Solèr et al. (2001) and Busse et al. (2001) assessed long-term control in patients with moderate-to-severe asthma receiving omalizumab therapy (Buhl et al. 2002b; Lanier et al. 2003). Participants could continue into a 24-week double-blind extension phase and be maintained on their randomized treatment and the lowest sustainable dose of inhaled corticosteroid. The use of concomitant asthma medication was permitted, and investigators could adjust the beclomethasone dipropionate dose or switch to another inhaled corticosteroid if considered necessary. Findings indicated that fewer numbers of exacerbations occurred in omalizumab-treated patients despite a sustained significant reduction in their use of inhaled corticosteroids when compared with the placebo control group $[P=0.023$ (Lanier et al. 2003) and $P<0.001$ (Buhl et al. $2002 b)]$, indicating that omalizumab is effective in the long-term control of allergic asthma.

Ayres et al. (2004) performed an open-label trial in patients with poorly controlled moderate-to-severe allergic asthma in which the addition of omalizumab to best standard care caused a reduction in the number of clinically significant asthma exacerbations per patient-year (1.12 versus 2.86; $P<0.001)$ compared with best standard care alone. This evidence highlights the potential benefit of using omalizumab as add-on therapy in patients with moderate-to-severe asthma.

\section{Severe allergic asthma}

Holgate et al. (2004) investigated the effect of omalizumab on patients with severe allergic asthma using high-dose inhaled fluticasone propionate. This study used similar methods to those of Solèr et al. (2001) and Busse et al. (2001); however the steroid reduction phase was 4 weeks longer, lasting 16 weeks. Median reductions in fluticasone dose were significantly greater 
with omalizumab than with placebo (60\% versus $50 \%$; $P=0.003)$. Omalizumab reduced rescue medication, improved asthma symptoms, and asthma-related quality of life compared with placebo through both phases of the study. This indicates that the effect of omalizumab translates to patients requiring high-dose inhaled corticosteroids and remains constant regardless of which type of inhaled corticosteroid patients are treated with.

The INNOVATE study (Humbert et al. 2005) examined the impact of omalizumab as add-on therapy in patients with severe persistent asthma inadequately controlled despite high-dose inhaled corticosteroids and LABAs (GINA 2002 step 4 treatment). This was a multicenter, randomized, placebo-controlled, doubleblind study comprising a 7-day screening period to evaluate eligibility, an 8-week run-in phase, a 28-week drug add-on treatment phase, and a 16-week follow-up phase. Results from 419 patients showed the addition of omalizumab reduced the severe exacerbation rate $(0.24$ versus $0.48 ; P=0.002)$ and emergency visit rate ( 0.24 versus $0.43 ; P=0.038)$. It also improved the clinically significant exacerbation rate (i.e. requiring systemic corticosteroids) during the 28-week treatment phase, however this had to be adjusted for an observed relevant imbalance in history of clinically significant asthma exacerbations to become statistically significant (0.68 versus $0.91 ; P=0.042)$. Asthmarelated quality of life, morning peak expiratory flow (PEF), and asthma symptom scores were also significantly improved in omalizumab recipients.

A meta analysis by Holgate et al. (2001) of three phase III trials (Busse et al. 2001; Solèr et al. 2001; Holgate et al. 2004) was conducted to determine the efficacy of omalizumab in a subgroup of patients at high-risk of serious asthma-related morbidity and mortality. High-risk patients were defined as those who had visited an emergency room, experienced overnight hospitalization, or received treatment in an intensive care unit during the last year, as well as those who had been intubated at some time prior to screening. This definition identified 254 high-risk patients from the total 1412 participants. The primary outcome measure was the annualized rate of significant asthma exacerbation episodes, those requiring a doubling of baseline inhaled corticosteroid dose, during the steroid stable phase. This meta analysis demonstrated that omalizumab reduced mean rates of significant exacerbation episode per patient-year in this high-risk group compared with placebo (0.69 versus 1.56; $P=0.007)$. In 93 patients with a history of hospitalization in the last year, fewer on omalizumab were rehospitalized during the study period $(4.5 \%$ versus $12.0 \%)$. Patients treated with omalizumab also showed significantly greater improvements from baseline in PEF $(P=0.026)$, overall asthma-related quality of life $(P=0.042)$, mean nocturnal $(P=0.007)$ and mean total $(P=0.011)$ asthma symptom scores compared with placebo.

\section{Emergency room visits}

Corren et al. (2003) analyzed the effects of omalizumab on serious asthma exacerbations in patients requiring treatment with inhaled corticosteroids for allergic asthma. They used data collected in three phase III studies: two in adults and adolescents (Busse et al. 2001; Solèr et al. 2001) and one trial involving children aged 6-12 years (Milgrom et al. 2001).

They found that the rate of unscheduled asthma-related outpatient visits was significantly lower per 100 patient-years in omalizumab-treated patients compared with those receiving placebo (21.3 versus 35.5 , rate ratio $=0.60 ; P<0.01$ ). There was also a statistically significant reduction in asthma-related emergency room visits per 100 patient-years (1.8 versus 3.8 , rate ratio $=0.47 ; P=0.05$ ). Hospitalizations due to asthma were $92 \%$ lower in omalizumab-treated patients compared with the placebo group $(P<0.01)$.

In addition, pooled analysis by Bousquet et al. (2005) from seven clinical trials revealed that omalizumab significantly reduced the rate of total emergency visits by $47 \%(P<0.001$ versus control) in patients with severe persistent asthma. This meta analysis also demonstrated a reduction in the rate of asthma exacerbations by $38 \%(P<0.0001$ versus control).

These results signify that treatment with omalizumab may confer benefits in quality of life, as well as economic advantages by reducing the amount of costly unscheduled healthcare.

\section{Quality of life}

Moderate-to-severe asthma has a substantial impact on patients' quality of life. Niebauer et al. (2006) summarized the asthmarelated quality of life outcomes associated with omalizumab in a meta analysis of five published clinical trials and extensions (Busse et al. 2001; Milgrom et al. 2001; Solèr et al. 2001; Buhl et al. 2002a; Lemanske et al. 2002; Finn et al. 2003; Holgate et al. 2004; Vignola et al. 2004), as well as unpublished clinical study reports from the manufacturer. The Juniper Asthma Quality of Life Questionnaire was used to measure asthma-related quality of life.

Omalizumab treatment resulted in a significant improvement of asthma-related quality of life score compared with placebo in the steroid reduction phase of each study $(P<0.05)$. Meta analysis illustrated this trend extending through the steroid stabilization $(P=0.003)$ and extension phases $(P=0.003)$, however, statistical significance was not achieved for each individual trial during these phases. Meta analysis also indicated a 1.6- to 2-fold increase in moderate $(\geq 1$ point) $(P<0.001)$ and 1.8- to 2.1 -fold increase in large $(\geq 1.5$ point $)(P<0.001)$ improvements in overall quality of life scores in omalizumab-treated patients compared with placebo during both steroid stabilization and steroid reduction. This analysis reveals the significant improvements in quality of life in patients with moderate-to-severe asthma through treatment with omalizumab.

Chipps et al. (2006) emphasized the effect of add-on omalizumab on asthma-related quality of life with a pooled analysis of six controlled clinical trials comprising 2548 patients (Busse et al. 2001; Solèr et al. 2001; Ayres et al. 2004; Holgate et al. 2004; Vignola et al. 2004; Humbert et al. 2005) (Table 4). They also found that omalizumab produced significantly greater improvements in Juniper Asthma Quality of Life Questionnaire total score $(P<0.001)$ and significantly more clinically meaningful improvements 
Table 4 | Effect of omalizumab on Juniper Asthma Quality of Life Questionnaire (AQLQ) compared with placebo in allergic asthma (reproduced from Chipps et al. 2006, with permission)

\begin{tabular}{|c|c|c|c|c|}
\hline \multirow[t]{2}{*}{ Asthma severity } & \multirow[t]{2}{*}{ Study } & \multicolumn{3}{|c|}{ Change from baseline in total AQLA score, least square mean (n) } \\
\hline & & Placebo & Omalizumab & $P$ value \\
\hline \multirow[t]{3}{*}{ Moderate/severe } & Busse et al. 2001 & $0.61(246)$ & $0.93(256)$ & $<0.001$ \\
\hline & Solèr et al. 2001 & $0.64(235)$ & $1.02(244)$ & $<0.001$ \\
\hline & Vignola et al. 2004 & $1.12(192)$ & $1.39(208)$ & 0.01 \\
\hline \multirow[t]{2}{*}{ Severe } & Holgate et al. 2004 & $0.18(152)$ & $0.46(158)$ & 0.011 \\
\hline & Humbert et al. 2005 & $0.49(205)$ & $0.94(204)$ & $<0.001$ \\
\hline
\end{tabular}

$(\geq 0.5$ point score increase) $(P<0.001)$ compared with patients in the control groups.

Unpublished data collected by Holgate et al. (2004) and analyzed by Walker et al. (2006) reiterated the clinically relevant improvements in quality of life in patients with severe asthma treated with omalizumab compared with placebo. More patients had a $>0.5$ change in Juniper score with omalizumab compared with placebo (57.5\% versus $38.6 \%$; $P<0.05)$. Further meta analysis also revealed that patients in two studies treated with subcutaneous omalizumab were more likely than their counterparts in the placebo group to rate asthma control as good or excellent during the steroid stable phase $(P<0.001)$. This trend continued in the steroid reduction phase [number needed to treat (NNT), 5].

\section{Symptom score}

Asthma symptom scores were calculated using a 0-4 point scale for daytime and nocturnal symptoms and $0-1$ point scale for symptoms on waking, as rated by patients, with a maximum score of 9. Analysis of these scores in three studies (Busse et al. 2001; Solèr et al. 2001; Holgate et al. 2004) by Walker et al. (2006), demonstrated that omalizumab therapy significantly decreased end of treatment asthma symptom scores during the stable steroid phase in patients with moderate-to-severe asthma. However this represented a reduction of just $10 \%$ from baseline values.

Significant reductions from baseline symptom scores were demonstrated by Humbert et al. (2005) and Vignola et al. (2004) in favor of omalizumab during the steroid stable phase $(P=0.023$ and $P=0.039$, respectively). This reduction did not occur in the pediatric population (Milgrom et al. 2001). During the steroid reduction phase in patients with moderate-to-severe asthma only Busse et al. (2001) described a significantly greater mean change in symptom scores from baseline with omalizumab compared with placebo.

\section{Lung function}

The evidence for the effect of omalizumab on lung function is conflicting. In adolescent and adult patients with moderate-tosevere asthma, two studies have shown small but significant improvements from baseline $\mathrm{FEV}_{1}$ of $2.8 \%(P=0.043)$ (Humbert et al. 2005) and $73 \mathrm{~mL}(P=0.032)$ (Vignola et al. 2004). However, the meta analysis by Walker et al. (2006) reported no significant difference in end of treatment $\mathrm{FEV}_{1}$ and morning PEF with subcutaneous omalizumab compared with placebo. A small but significant increase in morning PEF has been reported in patients treated with intravenous omalizumab compared with placebo (30.7 versus $11.3 \mathrm{~L} / \mathrm{min} ; P=0.007$ ) (Milgrom et al. 1999). There was no difference in $\mathrm{FEV}_{1}$ between the two groups.

The benefit of improved lung function in asthma on clinically relevant findings is unclear, with a poor association between lung function and both health-related quality of life (Wijnhoven et al. 2001) and reduced hospital admissions (Qureshi et al. 1998). The inconsistent effects of omalizumab on lung function despite improved asthma outcomes emphasize the uncertain relationship between asthma severity and lung function.

\section{Use in children}

Milgrom et al. (2001) evaluated the impact of omalizumab on the treatment of childhood asthma in 334 children aged 6-12 years with moderate to severe allergic asthma requiring inhaled corticosteroids (beclomethasone dipropionate). The study design and dosing was similar to that used in the studies of Busse et al. (2001) and Solèr et al. (2001). Children receiving omalizumab were able to decrease their beclomethasone dipropionate dose by a greater amount (median reduction 100\% versus $66.7 \%$; $P=0.001$ ), with a higher percentage able to withdraw inhaled corticosteroids completely, compared with the placebo group (55\% versus $39 \% ; P=0.004)$. Children receiving omalizumab also had significantly fewer asthma exacerbations during the steroid reduction phase $(18.2 \%$ versus $38.5 \% ; P<0.001)$, significantly fewer urgent unscheduled outpatient physician visits $(12.9 \%$ versus $30.3 \% ; P=0.001)$, fewer missed school days $(0.65$ versus 1.21 days; $P=0.04$ ), and fewer two or three consecutive night awakenings requiring rescue medication $(11.6 \%$ versus $21.1 \% ; P=0.002)$. There was no significant difference between asthma symptom scores or lung function measurements in each group.

The use of monthly injections of omalizumab may present a compliance problem in pediatric patients and this study reported a small number of withdrawals due to pain and fear of injection (Milgrom et al. 2001). This compliance issue may lead to an extra dilemma in the treatment of children. However, it is worth noting that over 200 children did tolerate treatment. 


\section{Safety and tolerability}

Omalizumab has been extensively evaluated for adverse events. Deniz and Gupta (2005) performed a pooled analysis of 12 clinical trials involving 5328 patients with moderate-to-severe persistent asthma. They reported the use of omalizumab to have a similar safety profile to that of the control group, with no significant differences between groups. Walker et al. (2006) analyzed safety data and revealed a significant increase in injection-site reactions in patients treated with subcutaneous omalizumab and inhaled corticosteroid compared with placebo and inhaled corticosteroid [odds ratio $=2,95 \%$ confidence interval $(\mathrm{Cl}) 1.37,2.92$, control event rate $=5.5 \%$ ], which they calculated to equate to an NNT of 21. They described no difference in the number of patients with urticaria, headache, adverse events, or withdrawal due to adverse events. However, the exact number of studies and patients involved in this analysis was not stated.

Anaphylaxis occurred in three patients who received omalizumab during clinical trials, representing approximately $1 \%$ of all patients receiving the drug. In postmarketing surveillance, the frequency of anaphylaxis was estimated to occur in $0.2 \%$ of patients treated with omalizumab, based on an estimated 57300 patients treated with omalizumab (Anon 2007). Anaphylactic reactions have included urticaria, bronchospasm, syncope, hypotension, and/or angioedema of the throat and tongue. This led to the US FDA releasing an alert in February 2007 , updated in July 2007, regarding the risk of anaphylaxis in patients receiving omalizumab (FDA 2007). The FDA advises that omalizumab should only be administered in a healthcare setting under direct medical supervision and that patients are observed for an appropriate length of time after administration.

Malignant neoplasms have been reported in 25 of 5015 (0.5\%) omalizumab-treated patients compared with five of 2854 $(0.2 \%)$ control patients in completed clinical trials (Fernandez et al. 2005). A comparison of cancer rates with the US National Institutes of Health (NIH) SEER database found that the standardized incidence ratio of observed to expected number of events with omalizumab was similar to that expected in the general population, and in the control group it was one-third of that expected $(95 \% \mathrm{Cl}, 0.55,1.62$ versus $0.04,1.11)$. No cases of malignant neoplasm were considered drugrelated by a panel of independent oncologists, blinded to treatment assignment (Fernandez et al. 2005).

It has been postulated that $\lg \mathrm{E}$ initiates an antibody dependent cell-mediated cytotoxic response against helminthic parasites (Winter et al. 2000). This has lead to concern that treatment with omalizumab may adversely affect immunity and increase susceptibility of helminth infection. Cruz et al. (2007) conducted a randomized, double-blind, placebo-controlled trial in 137 patients at high risk of geohelminth infection. Although there was an increased frequency geohelminth infection in omalizumab recipients (50\% versus $41 \%$ ), it was not statistically significant (OR $1.47,95 \% \mathrm{Cl} 0.74,2.95)$. This suggests that omalizumab does not cause increased susceptibility to helminthic parasites.

\section{Safety in children}

Berger et al. (2003) evaluated the long-term effects of omalizumab in children by performing a 24-week extension to the study by Milgrom et al. (2001), and completing a safety analysis of the core study. All 309 children received open-label omalizumab in addition to other asthma medications during the extension phase. The incidence of adverse events in patients treated with omalizumab for 52 weeks was similar to those treated for 28 weeks in the core trial, which was generally comparable to placebo. Urticaria was reported in 11 patients (4.9\%), which resolved spontaneously or with antihistamine, apart from severe urticaria in one patient that necessitated omalizumab therapy discontinuation. No anaphylactic reactions or adverse events suggestive of serum sickness or immune complex formation occurred, and antiomalizumab antibodies were not detected in any child. The most frequently reported adverse events were upper respiratory tract infections $(47.1 \%)$ and headache $(42.7 \%)$. The authors concluded that long-term treatment with omalizumab is safe and well tolerated in children with allergic asthma, however further studies producing similar results would be required to verify this.

\section{Pregnancy}

No clinical studies of omalizumab in pregnant women have been performed but animal studies investigating the effects of high dose omalizumab $(75 \mathrm{mg} / \mathrm{kg})$ throughout reproduction have been conducted. Maternal toxicity, embryotoxicity or teratogenicity were not evident during organogenesis and there were no adverse effects on fetal or neonatal growth throughout late gestation, delivery, and nursing.

However, animal studies are not always predictive of human response. Omalizumab may cross the placental barrier and be excreted in breast milk, in a similar manner to $\mathrm{lgG}$, and the risk of harm to a fetus or nursing infant is unknown. Omalizumab should only be used during pregnancy if absolutely required to maintain asthma control and caution should be exercised (Anon 2007). A pregnancy exposure registry has been initiated to monitor the pregnancy outcomes in women exposed to omalizumab, including women who receive one or more doses of omalizumab within 8 weeks prior to conception or any time during pregnancy. These women will be followed up to the completion of their pregnancy and evaluation of their infants will be conducted at birth, 6, and 12 months (Anon 2006).

\section{Outstanding questions with omalizumab}

The above studies have demonstrated that omalizumab significantly reduces asthma exacerbations when used as a steroid-sparing agent and as adjunctive therapy to inhaled corticosteroids and LABAs in patients with moderate and severe asthma, who are at step $3 / 4$ in the GINA and BTS/SIGN guidelines. Its role in patients who are at step 5 in the BTS/SIGN and GINA guidelines and require oral corticosteroids remains uncertain. Walker et al. (2006) describe that omalizumab had no significant effect on asthma exacerbations or reduction in daily oral steroid dose from data collected in one study (Holgate et al. 
2004) and there were insufficient data to justify the extrapolation of the findings to this subgroup. In the INNOVATE study (Humbert et al. 2005), which showed a significant reduction in the severe exacerbation rate and the emergency visit rate, two thirds of patients were receiving additional controller medications, including $22 \%$ on maintenance oral corticosteroids. The evidence for the use of omalizumab in patients on oral corticosteroids remains limited, however, these are the very patients who suffer from refractory asthma and are being targeted for treatment with omalizumab. Further studies tailored towards the evaluating the efficacy of omalizumab in patients requiring oral corticosteroids are therefore required.

The size of the placebo effect is striking in these clinical trials. Patients receiving placebo were able to reduce the amount of inhaled corticosteroid they required by significant amounts (Walker et al. 2006). These effects may be due to close monitoring of patients throughout the trials resulting in better compliance with inhaled corticosteroids. This brings into question the true steroid-sparing effect of omalizumab and how much of its shown efficacy is related to study design and patient population.

The steroid-sparing effects of omalizumab in moderate-tosevere asthma, although statistically significant compared with placebo, remain quite modest (weighted mean difference $-118 \mathrm{mcg}$ beclomethasone equivalent per day, $95 \% \mathrm{Cl}-154$, -84) and there was a high degree of variability between studies (Walker et al. 2006). This outcome has not been fully investigated in patients with severe asthma who are at higher risk of serious steroid side effects. The available evidence and the large placebo effect bring into doubt the cost effectiveness of omalizumab as a steroid-sparing agent.

Omalizumab has an inconsistent effect on lung function with no definite benefit evident. This conflicting evidence may highlight the unclear relationship between improved lung function and clinically relevant asthma outcomes (Qureshi et al. 1998; Wijnhoven et al. 2001). However, all other asthma medication has been licensed on the basis of this outcome. The true impact of omalizumab on lung function may be obscured by the accompanying background inhaled therapy used throughout these studies.

The efficacy of omalizumab on asthma symptoms in patients with moderate and severe disease remains uncertain. Significant reductions in end of treatment symptoms scores occurred during the steroid stable phases of treatment (Busse et al. 2001; Solèr et al 2001; Holgate et al 2004), however, this only represented a reduction of approximately $10 \%$ from baseline scores (Walker et al. 2006). Nonetheless, there was indication that omalizumab is more beneficial to symptoms in the more severe patient population with significant reductions from baseline symptom scores (Humbert et al. 2005).

Not all patients respond to omalizumab treatment, with approximately $16 \%$ of patients with severe asthma unable to reduce their inhaled steroid dose by more than $25 \%$ throughout the steroid reduction phase (Walker et al. 2006). To identify those who would achieve greatest benefit from omalizumab, Bousquet et al. (2004) reviewed results from 1070 patients in two phase III studies (Busse et al. 2001; Solèr et al. 2001). A composite definition of response required no asthma exacerbation during 16 weeks of treatment and response in at least one of the following: reduced symptom scores, reduced usage of medication, improved lung function, or improved quality of life. Three baseline variables predictive of best response to add-on omalizumab were ascertained. A history of emergency asthma treatment in the past year was the most predictive $(P=0.015)$, followed by treatment with high-dose ( $\geq 800 \mathrm{mcg} /$ day) beclomethasone dipropionate $(P=0.037)$, and an $\mathrm{FEV}_{1} \leq 65 \%$ predicted $(P=0.072)$. A more recent analysis (Bousquet et al. 2007) using data from the INNOVATE study (Humbert et al. 2005) revealed the only pretreatment baseline characteristic predictive of a superior response to omalizumab was baseline total IgE, which was not found to be predictive in the study by Bousquet et al. (2004). Although subjective, the physicians' overall assessment of treatment was determined as the most meaningful measure of response to omalizumab therapy, with approximately $61 \%$ of the overall omalizumab-treated population identified as responders. This should occur at 16 weeks, which would allow patients to achieve maximum benefit (Bousquet et al. 2004). These results highlight the difficulty in trying to predict which patients will gain most benefit from omalizumab and therefore the resultant problem in optimizing the use of healthcare resources. Nonetheless, the recognition of the physicians' overall assessment of treatment can potentially be used to determine whether treatment should continue beyond an initial 16-week trial.

\section{Economic evidence}

Omalizumab is an expensive novel treatment that costs approximately $£ 15400$ per patient per annum in the UK if the maximum recommended dose is administered every 2 weeks (NICE 2007). A retrospective economic analysis using data from two randomized controlled clinical trials (Busse et al. 2001; Solèr et al. 2001) found the cost to achieve an additional successfully controlled day was \$US523 and the daily cost to achieve at least a 0.5 point increase in the Asthma Quality of Life Questionnaire score was \$US378 in 2003. Omalizumab could be cost saving if given to nonsmoking allergic asthmatic patients with poorly controlled symptoms despite maximal therapy who are hospitalized five or more times or for 20 days or more each year (Oba \& Salzman 2004).

A Markov model comparing lifelong standard therapy with a treatment period of omalizumab add-on therapy followed by standard therapy was developed using data from the INNOVATE study (Humbert et al. 2005) and adapted towards a Swedish societal prospective. This revealed that omalizumab add-on therapy cost an additional $€ 42754$ for 0.76 additional qualityadjusted life years (QALYs) resulting in an incremental costeffectiveness ratio (ICER) of $€ 56091$ (95\% Cl €31 328, €120 552). The analysis concluded that omalizumab provides cost offsets and may have an attractive ICER in treating severe allergic asthma (Dewilde et al. 2006). 
A lower ICER of $€ 31209$ (95\% Cl $€ 27739$, $€ 40$ 840) was determined for adding omalizumab to standard therapy using data from the real-life 1-year randomized open-label study (ETOPA) and using Canada as a reference country (Brown et al. 2007). Only patients receiving high-dose inhaled corticosteroids plus LABA were included in the analysis.

The NICE Evidence Review Group (ERG) calculated ICERs for different scenarios using data from the INNOVATE (Humbert et al. 2005) primary intention-to-treat population that ranged from $£ 33300$ to $£ 40900$ per QALY gained (NICE 2007). Scenario analyses for the high-risk hospitalization subgroup ranged from £29800 to £34300 per QALY gained. The ERG's amended probabilistic sensitivity analysis showed a mean ICER of $£ 38900$ per QALY gained. They estimated omalizumab as addon therapy to have a $23.6 \%$ probability of being cost effective, using a threshold willingness to pay of $£ 30000$ per QALY (NICE 2007). In the NICE final appraisal determination of omalizumab for severe persistent allergic asthma the Appraisal Committee concluded that the ICER was higher than acceptable for patients with severe persistent allergic asthma (NICE 2007). They did, however, agree that for a narrowly defined severely affected group of asthmatics, at an elevated risk of asthma mortality, costeffective treatment with omalizumab was possible if therapy was discontinued in nonresponders at 16 weeks and if vial wastage could be minimized to reduce costs.

\section{Patient group/population}

The NICE Appraisal Committee (NICE 2007) in England and Wales recommends that omalizumab add-on therapy is used as an option for the treatment of asthma in adults and adolescents (12 years and older) with severe unstable disease. This is defined as those who have had either two or more severe exacerbations of asthma requiring hospital admission within the previous year, or three or more severe exacerbations of asthma within the previous year, at least one of which required admission to hospital, and a further two which required treatment or monitoring in excess of the patients' usual regimen in an accident and emergency unit. These patients must have a full trial of, and documented compliance with, inhaled high-dose corticosteroids and LABA in addition to leukotriene receptor antagonists, theophyllines, oral corticosteroids, and oral beta ${ }_{2}$ agonists, and smoking cessation where clinically appropriate. They require confirmation of lgEmediated allergy to a perennial allergen by clinical history and allergy skin testing. Omalizumab should be discontinued at 16 weeks in patients who have not shown an adequate response to therapy (NICE 2007).

The BTS/SIGN guidelines state that there are no active comparative studies and it is therefore not yet possible to place omalizumab in the stepwise treatment of asthma (BTS,SIGN 2007). However, the worldwide GINA guidelines include the addition of omalizumab for patients whose symptoms are not controlled despite combination therapy including high doses of inhaled corticosteroids, LABA, and oral steroid treatment (GINA 2006b).
There is insufficient evidence to support the use of omalizumab in children with severe persistent allergic asthma. Although two studies in this population have shown similar results to studies in adolescents and adults, further evaluation of this agent in children is required.

\section{Dosage, administration, and formulations}

Omalizumab (Xolair) is available for injection in $150 \mathrm{mg}$ vials of powder for reconstitution. Doses ranging from 150 to $375 \mathrm{mg}$ are administered subcutaneously every 2 or 4 weeks. The dose of omalizumab $(\mathrm{mg})$ and dosing frequency are determined by serum total $\lg \mathrm{E}(\mathrm{IU} / \mathrm{mL})$ measured before the start of treatment and bodyweight $(\mathrm{kg})$. Dose determination charts are used to assign the appropriate dose (Tables $5 a$ and b). Doses of more than $150 \mathrm{mg}$ are divided among more than one injection site, with not more than $150 \mathrm{mg}$ per site.

\begin{tabular}{|l}
$\begin{array}{l}\text { Table 5a | Omalizumab dose (mg) administered by } \\
\text { subcutaneous injection every } \mathbf{4} \text { weeks for } \\
\text { adults and adolescents (12 years of age and } \\
\text { older) with asthma (Anon. 2007) }\end{array}$ \\
\begin{tabular}{|lcccc|}
\hline $\begin{array}{l}\text { Pretreatment } \\
\text { serum IgE } \\
\text { (IU/mL) }\end{array}$ & $30-60$ & $>60-70$ & $>70-90$ & $>90-150$ \\
\hline$\geq 30-100$ & 150 & 150 & 150 & 300 \\
$>100-200$ & 300 & 300 & 300 & \\
$>200-300$ & 300 & See below & & \\
$>300-400$ & & & & \\
$>400-500$ & & & \\
$>500-600$ & & & \\
\end{tabular}
\end{tabular}

\begin{tabular}{|c|c|c|c|c|}
\hline \multirow{2}{*}{$\begin{array}{l}\text { Pretreatment } \\
\text { serum IgE } \\
(\mathrm{IU} / \mathrm{mL})\end{array}$} & \multicolumn{4}{|c|}{ Bodyweight } \\
\hline & $30-60$ & $>60-70$ & $>70-90$ & $>90-150$ \\
\hline \multicolumn{5}{|l|}{$\geq 30-100$} \\
\hline$>100-200$ & & & & 225 \\
\hline$>200-300$ & & 225 & 225 & 300 \\
\hline$>300-400$ & 225 & 225 & 300 & \\
\hline$>400-500$ & 300 & 300 & 375 & \\
\hline$>500-600$ & 300 & 375 & Do not use & \\
\hline$>600-700$ & 375 & & & \\
\hline
\end{tabular}

It is unclear whether omalizumab is therapeutically effective in obese patients whose bodyweight falls outside the dosing guidelines. Kwong and Jones (2006) describe how the maximum dose of omalizumab reduced the systemic steroid requirements 
of two obese pediatric patients with severe persistent asthma, and one patient required fewer daily inhaled corticosteroids. Further studies into the efficacy of omalizumab in patients whose weight falls outside the dosing guidelines are required.

\section{Place in therapy}

Current clinical evidence indicates that omalizumab is an effective add-on therapy in patients with severe persistent allergic asthma. This is demonstrated by improvements in important clinical outcomes such as exacerbation rates, emergency visit rates, symptom scores, and quality of life scores. Omalizumab gives physicians a further therapeutic option in the management of patients with therapy-resistant disease and it is this subgroup that has the potential to benefit the most. However, the role of omalizumab in patients requiring maintenance oral steroid therapy remains unclear and further studies are required to demonstrate efficacy in this population. Difficulty in identifying patients who will respond to this expensive novel therapy prior to treatment also creates problems with resource utilization. NICE has recommended that cost-effective treatment with omalizumab is possible in severe adult asthmatics with a high risk of asthma-related mortality provided that treatment is discontinued in nonresponders after 16 weeks. Additional evidence is required to assess the impact and safety of omalizumab in children with severe allergic asthma.

\section{References}

Anon. International consensus report on the diagnosis and treatment of asthma. National Heart, Lung, and Blood Institute, National Institutes of Health. Eur Respir J. 1992;5:601-641.

Anon. The xolair pregnancy registry: an observational study of the use and safety of xolair (Omalizumab) during pregnancy (EXPECT). ClinicalTrials. gov. Nov 9, 2006. Available at: http://www.clinicaltrials.gov/ct/show/ NCT00373061?order=1 (accessed September 15, 2007).

Anon. Xolair prescribing information. Available at: http://www.gene.com/gene/ products/information/pdf/xolair-prescribing.pdf (accessed July 20, 2007).

ATS (American Thoracic Society). Proceedings of the ATS workshop on refractory asthma: current, understanding, recommendations, and unanswered questions. Am J Respir Crit Care Med. 2000;162:2341-2351.

Ayres JG, Higgins B, Chilvers ER, Ayre G, Blogg M, Fox H. Efficacy and tolerability of anti-immunoglobulin $E$ therapy with omalizumab in patients with poorly controlled (moderate-to-severe) allergic asthma. Allergy. 2004;59:701708.

Barnes, PJ. Anti-lgE therapy in asthma: rationale and therapeutic potential. Int Arch Allergy Immunol. 2000;123:196-204.

Barnes PJ. Anti-lgE therapy in asthma. 2007. Available at: www.uptodate.com (accessed August 19, 2007).

Berger W, Gupta N, McAlary M, Fowler-Taylor A. Evaluation of long-term safety of the anti-IgE antibody, omalizumab, in children with allergic asthma. Ann Allergy Asthma Immunol. 2003;91:182-188

Boulet LP, Chapman KR, Côtè J, et al. Inhibitory effects of an anti-lgE antibody E25 on allergen-induced early asthmatic response. Am J Respir Crit Care Med. 1997;155:1835-1840.

Bousquet J, Wenzel S, Holgate S, Lumry W, Freeman P, Fox H. Predicting response to omalizumab, an anti-lgE antibody, in patients with allergic asthma. Chest. 2004;125:1378-1386.
Bousquet J, Cabrera P, Berkman N, et al. The effect of treatment with omalizumab, an anti-IgE antibody, on asthma exacerbations and emergency medical visits in patients with severe persistent asthma. Allergy. 2005;60:302308.

Bousquet J, Rabe K, Humbert M, et al. Predicting and evaluating response to omalizumab in patients with severe allergic asthma. Respir Med. 2007;101:1483-1492.

Brown R, Turk F, Dale P, Bousquet J. Cost-effectiveness of omalizumab in patients with severe persistent allergic asthma. Allergy. 2007;62:149-153.

BTS, SIGN (British Thoracic Society, Scottish Intercollegiate Guidelines Network). British guideline on the management of asthma. Available at: http:// www.brit-thoracic.org.uk/c2/uploads/asthma_fullguideline2007.pdf (accessed August 15, 2007).

Buhl R, Hanf G, Solèr M, et al. The anti-IgE antibody omalizumab improves asthma-related quality of life in patients with allergic asthma. Eur Respir J. 2002a;20:1088-1094

Buhl R, Solèr M, Matz J, et al. Omalizumab provides long-term control in patients with moderate-to-severe allergic asthma. Eur Respir J. 2002b;20:7378.

Busse W, Corren J, Lanier BQ, et al. Omalizumab, anti-IgE recombinant humanized monoclonal antibody, for the treatment of severe allergic asthma. J Allergy Clin Immunol. 2001;108:184-190.

Chipps B, Buhl R, Beeh KM, Fox H, Thomas K, Reisner C. Improvement in quality of life with omalizumab in patients with severe allergic asthma. Curr Med Res Opin. 2006;22:2201-2208.

Corne, J, Djukanovic, R, Thomas L, et al. The effect of intravenous administration of a chimeric anti-lgE antibody on serum IgE levels in atopic subjects: efficacy, safety, and pharmacokinetics. J Clin Invest. 1997;99:879887.

Corren J, Casale T, Deniz Y, Ashby M. Omalizumab, a recombinant humanized anti-IgE antibody, reduces asthma-related emergency room visits and hospitalizations in patients with allergic asthma. J Allergy Clin Immunol. 2003;111:87-90.

Cruz AA, Lima F, Sarinho E, et al. Safety of anti-immunoglobulin E therapy with omalizumab in allergic patients at risk of geohelminth infection. Clin Exp Allergy. 2007;37:197-207.

de Vries JE, Carballido JM, Aversa G. Receptors and cytokines involved in allergic TH2 cell responses. J Allergy Clin Immunol.1999;103:S492-S496.

Deniz YM, Gupta N. Safety and tolerability of omalizumab (Xolair), a recombinant humanized monoclonal anti-IgE antibody. Clin Rev Allergy Immunol. 2005;29:31-48.

Dewilde S, Turk F, Tambour M, Sandström T. The economic value of anti-lgE in severe persistent, IgE-mediated (allergic) asthma patients: adaptation of INNOVATE to Sweden. Curr Med Res Opin. 2006;22:1765-1776.

Drazen JM. Pathogenesis of asthma. Available at: www.uptodate.com (accessed August 19, 2007).

Fahy, JV. Reducing IgE levels as a strategy for the treatment of asthma. Clin Exp Allergy. 2000;30(Suppl. 1):16-21.

Fahy JV, Fleming HE, Wong $\mathrm{HH}$, et al. The effect of an anti-lgE monoclona antibody on the early- and late-phase responses to allergen inhalation in asthmatic subjects. Am J Respir Crit Care Med. 1997;155:1828-1834.

Fahy JV, Cockcroft DW, Boulet LP, et al. Effect of aerosolized anti-IgE (E25) on airway responses to inhaled allergen in asthmatic subjects. Am J Respir Crit Care Med. 1999;160:1023-1027.

FDA (Food and Drug Administration). Information for healthcare professionals: Omalizumab. July 2, 2007. Available at: www.fda.gov/cder/drug/infopage/ omalizumab/default.htm (accessed July 20, 2007).

Fernandez C, Busse W, Reisner C, Gupta N. Clinical data do not suggest a causal relationship between omalizumab therapy and cancer. Poster presented at: American Thoracic Society International Conference; May 20-25, 2005; San Diego, CA. Poster G50. 
Finn A, Gross G, van Bavel J, et al. Omalizumab improves asthma-related quality of life in patients with severe allergic asthma. J Allergy Clin Immunol. 2003;111:278-284.

GINA (Global Initiative for Asthma). Global strategy for asthma management and prevention. 2006a. Available at: http://www.ginasthma.com/ GuidelinesResources.asp?|1=2\&l2=0 (accessed August 25, 2007)

GINA (Global Initiative for Asthma). Pocket guide for asthma management and prevention. 2006b. Available at: http://www.ginasthma.com/Guideitem. asp??11=2\&1\&intID=37 (accessed August 25, 2007).

Guachat JF, Lebman DA, Coffman RL, Gascon H, de Vries JE. Structure and expression of germline epsilon transcripts in human $B$ cells induced by interleukin 4 to switch to IgE production. J Exp Med. 1990;172:463-473.

Heaney LG, Conway E, Kelly C, et al. Predictors of therapy resistant asthma outcome of a systemic evaluation protocol. Thorax. 2003;58:561-566.

Holgate S, Bousquet J, Wenzel S, Fox H, Liu J, Castellsague J. Efficacy of omalizumab, an anti-immunoglobulin $\mathrm{E}$ antibody, in patients with allergic asthma at high risk of serious asthma-related morbidity and mortality. Curr Med Res Opin. 2001;17:233-240.

Holgate ST, Chuchalin AG, Hebért J, et al; Omalizumab 011 International Study Group. Efficacy and safety of a recombinant anti-immunoglobulin $\mathrm{E}$ antibody (omalizumab) in severe allergic asthma. Clin Exp Allergy. 2004;34:632-638.

Humbert M, Beasley R, Ayres J, et al. Benefits of omalizumab as add-on therapy in patients with severe persistent asthma who are inadequately controlled despite best available therapy (GINA 2002 step 4 treatment): INNOVATE. Allergy. 2005;60:309-316.

Just J, Sahraoui F, Le Gros V, Grimfeld A. Effectiveness of omalizumab in monozygotic twin sisters with severe allergic asthma. Allergy. 2007;62:453454.

Kwong KY, Jones CA. Improvement of asthma control with omalizumab in 2 obese pediatric asthma patients. Ann Allergy Asthma Immunol. 2006;97:288293.

Lanier BQ, Corren J, Lumry W, Liu J, Fowler-Taylor A, Gupta N. Omalizumab is effective in the long-term control of severe allergic asthma. Ann Allergy Asthma Immunol. 2003;91:154-159.

Lemanske RF Jr, Nayak A, McAlary M, Everhard F, Fowler-Taylor A, Gupta N. Omalizumab improves asthma-related quality of life in children with allergic asthma. Pediatrics. 2002;110:e55.

Liebhaber M, Dyer Z. Home therapy with subcutaneous anti-immunoglobulin-E antibody omalizumab in 25 patients with immunoglobulin-E-mediated (allergic) asthma. J Asthma. 2007;44:195-196.

Luskin AT, Kosinski M, Bresnahan BW, Ashby M, Wong DA. Symptom control and improved functioning: the effect of omalizumab on asthma-related quality of life (ARQL). J Asthma. 2005;42:823-827.

MacGlashan DW. Releasability of human basophils: cellular sensitivity and maximal histamine release are independent variables. J Allergy Clin Immunol. 1993;91:605-615.

Masoli M, Fabian D, Holt S, Beasley R. Global burden of asthma. 2004. Available at: http://www.ginasthma.com/Reportltem.asp?l1=2\&l2=2\&intld=94 (accessed August 4, 2007).

Milgrom H, Fick RB Jr, Su JQ, et al. Treatment of allergic asthma with monoclonal anti-IgE antibody. rhuMAb-E25 Study Group. N Engl J Med. 1999;341:1966-1973.
Milgrom $\mathrm{H}$, Berger W, Nayak A, et al. Treatment of childhood asthma with antiimmunoglobulin E antibody (omalizumab). Pediatrics. 2001;108:e36.

NICE (National Institute for Health and Clinical Excellence). Final appraisal determination - omalizumab for severe persistent allergic asthma. 2007. Available at: http://guidance.nice.org.uk/page.aspx?o=450310 (accessed August 31, 2007)

Niebauer K, Dewilde S, Fox-Rushby J, Revicki DA. Impact of omalizumab on quality-of-life outcomes in patients with moderate-to-severe allergic asthma. Ann Allergy Asthma Immunol. 2006;96:316-326.

Oba Y, Salzman GA. Cost-effectiveness analysis of omalizumab in adults and adolescents with moderate-to-severe allergic asthma. J Allergy Clin Immunol. 2004;114:265-269.

Presta LG, Lahir SJ, Sheilds RL, et al. Humanization of an antibody directed against IgE. J Immunol. 1993;151:2623-2632.

Prieto L, Gutiérrez V, Colás C, et al. Effect of omalizumab on adenosine 5'-monophosphate responsiveness in subjects with allergic asthma. Int Arch Allergy Immunol. 2006;139:122-131.

Qureshi F, Pestian J, Davis P, Zaritsky A. Effect of nebulized ipratropium on the hospitalization rates of children with asthma. N Engl J Med. 1998;339:10301035.

Robinson DS, Campbell DA, Durham SR, Pfeffer J, Barnes PJ, Chung KF; Asthma and Allergy Research Group of the National Heart and Lung Institute. Systematic assessment of difficult-to-treat asthma. Eur Respir J. 2003;22:478483.

Solèr M, Matz J, Townley R, et al. The anti-IgE antibody omalizumab reduces exacerbations and steroid requirement in allergic asthmatics. Eur Respir $J$. 2001;18:254-261.

Turner $\mathrm{H}$, Kinet JP. Signalling through the high-affinity IgE receptor FceRI. Nature. 1999;402:B24-B30.

van Rensen ELJ, Evertse CE, van Schadewijk WAA, et al. Anti-IgE omalizumab treatment reduces allergen-induced eosinophilia in biopsies and sputum in patients. Abstract presented at: American Thoracic Society International Conference, May 20-25, 2005: San Diego, CA.

Vignola AM, Humbert M, Bousquet J, et al. Efficacy and tolerability of antiimmunoglobulin $E$ therapy with omalizumab in patients with concomitant allergic asthma and persistent allergic rhinitis: SOLAR. Allergy. 2004:59:709_ 717.

Walker S, Monteil M, Phelan K, Lasserson TJ, Walters EH. Anti-IgE for chronic asthma in adults and children. Cochrane Database Syst Rev. 2006;(2):CD003559.

Wijnhoven HA, Kriegsman DM, Hesselink AE, Penninx BW, de Haan M. Determinants of different dimensions of disease severity in asthma and COPDpulmonary function and health-related quality of life. Chest. 2001;119:10341042.

Winter WE, Hardt NS, Fuhrman S. Immunoglobulin E: importance in parasitic infections and hypersensitivity responses. Arch Pathol Lab Med. 2000;124:1382-1385.

Correspondence: Dr Liam Heaney, Regional Respiratory Centre, Belfast City Hospital, Lisburn Road, Belfast BT9 7AB, UK or at I.heaney@qub.ac.uk 